\title{
Desain Lingkungan Kerja Berdasarkan Pendekatan Kesehatan dan Keselamatan Kerja
}

\author{
Eko Nursubiyantoro ${ }^{1}$, Wahyu Wibowo Eko Yulianto ${ }^{1}$ \\ ${ }^{1}$ Jurusan Teknik Industri, Fakultas Teknik Industri, \\ Universitas Pembangunan Nasional Veteran Yogyakarta \\ Jl. Babarsari 2 Tambakbayan, Yogyakarta 55281 \\ Telp (0274) 485268, Fax (0274) 486256 \\ email :ekonsby072@upnyk.ac.id. \\ doi: https://doi.org/10.31315/opsi.v12i2.3101
}

Received: $16^{\text {th }}$ October 2019; Revised: $26^{\text {th }}$ November 2019; Accepted: $30^{\text {th }}$ December 2019, Available online: $31^{\text {st }}$ December 2019; Published regularly: December 2019

\begin{abstract}
Kalasan Fried Chicken Industry Center is one of the home industries producing fried chicken in Yogyakarta. Initial measurements obtained from the working environment conditions of occupational health and safety are still considered to be less than comfortable and in accordance with standards. As a result of lack of lighting and high room temperature, workers often experience eye fatigue, dizziness, frequent loss of focus and poor quality fried chicken production. Occupational health and safety according to the standard, it is necessary to improve the lighting aspect with the Lumen Method (Lumen Method or Zonal Cavacity Method, ZCM), the physical environment in terms of temperature is designed by increasing the fan capacity needed by the work environment so that the number and type of fans with quality can be determined the right air for the room. The lighting needs of the work environment are 924 watt lights and an exhaust fan and sufficient air volume. The results of the implementation were able to increase the level of lighting and temperature in accordance with work comfort.
\end{abstract}

Keywords: Work environment; K3 design; Increased production

\begin{abstract}
ABSTRAK
Sentra Industri Ayam Goreng Kalasan merupakan salah satu home industry yang memproduksi ayam goreng kremes di Yogyakarta. Pengukuran awal diperoleh kondisi lingkungan kerja dari kesehatan dan keselamatan kerja dirasa masih kurang dari rasa nyaman dan sesuai standar. Akibat dari kurangnya pencahayaan dan tingginya temperatur ruang, pekerja sering mengalami lelah mata, pusing, sering hilang fokus dan hasil produksi ayam goreng kurang berkualitas. Kesehatan dan keselamatan kerja yang sesuai standar, maka diperlukan perbaikan Segi pencahayaan dengan Metode Lumen (Lumen Method atau Zonal Cavacity Method, ZCM), lingkungan fisik dari segi temperatur dirancang dengan menambah kapasitas kipas yang dibutuhkan lingkungan kerja sehingga dapat ditentukan jumlah dan tipe kipas dengan kualitas udara yang tepat untuk ruangan tersebut. Kebutuhan pencahayaan lingkungan kerja sebanyak 9 lampu berdaya 24 watt dan sebuah exhaust fan dan volume udara yang cukup. Hasil implementasi mampu menaikkan tingkat pencahayaan dan temperatur yang sesuai dengan kenyamanan kerja.
\end{abstract}

Kata Kunci: lingkungan kerja; desain K3; peningkatan produksi.

\section{PENDAHULUAN}

Sentra Ayam Goreng Kremes Kalasan adalah sentra yang mengolah ayam goreng yang khas dari Kalasan, Sleman, Yogyakarta. Sentra Ayam Goreng Kremes Kalasan memiliki 2 stasiun kerja yaitu stasiun kerja penggorengan yang meliputi pembumbuan, penggorengan, dan penirisan ayam goreng dan stasiun kerja pengepakan yang meliputi kegiatan membungkus ayam goreng untuk siap dijual. Di stasiun kerja penggorengan terdapat berbagai keluhan yang dirasakan oleh pekerja. Keluhan yang muncul berupa pusing, lelah mata, hilang fokus dan gosong dalam menggoreng. Mereka mengungkapkan bahwa keluhan tersebut dikarenakan akibat minimnya pencahayaan dan tingginya temperatur pada stasiun kerja penggorengan tersebut. Berdasarkan penelitian yang dilakukan, maka perlu dilakukan evaluasi terhadap tingkat pencahayaan dan temperatur di stasiun kerja penggorengan yang kemudian ditentukan perancangan lingkungan kerja yang sesuai standar. Menurut Sutalaksana dkk (1979) ergonomi didefinisikan sebagai suatu cabang ilmu yang sistematis untuk memanfaatkan informasi mengenai sifat, kemampuan dan keterbatasan manusia untuk merancang suatu 
sistem kerja sehingga orang dapat hidup dan bekerja pada sistem itu dengan baik yaitu mencapai tujuan yang diinginkan melalui pekerjaan itu dengan efektif, nyaman dan aman. Lingkungan kerja merupakan segala sesuatu yang berada di sekitar tempat kerja yang langsung berhubungan dengan manusia dan lingkungan perantara. Lingkungan kerja dikatakan baik apabila kondisi saat bekerja mampu memberikan motivasi untuk bekerja akan berpengaruh terhadap semangat karyawan dalam bekerja.

Setiap pekerjaan baik di kantor maupun di industri, umumnya terdiri atas banyak aktivitas visual. Dalam melakukan pekerjaan apapun, kondisi pencahayaan yang tertata dengan baik akan meningkatkan kemampuan dalam melihat detail. Intensitas penerangan yang baik ditentukan oleh sifat dan jenis pekerjaan dimana pekerjaan yang teliti memerlukan intensitas penerangan yang lebih besar (Suma'mur, 1996). Pencahayaan tempat kerja yang memadai baik yang alami atau buatan, memegang peranan yang cukup penting dalam upaya peningkatan kesehatan, keselamatan dan produktivitas tenaga kerja. Baik tidaknya pencahayaan disuatu tempat kerja. Cahaya pada dasarnya adalah radiasi gelombang elektromagnetik yang dapat terlihat oleh mata manusia (Bridger, 2003). Salah satu pendekatan yang dapat dilakukan untuk mengetahui apakah kondisi pencahayaan di suatu tempat telah memenuhi standar adalah dengan mengukur iluminansi (illuminance) dari suatu sumber cahaya. Iluminansi adalah suatu ukuran banyaknya cahaya yang jatuh pada suatu permukaan atau benda kerja. Disamping tingkat iluminansi, perlu juga mengetahui luminansi (luminance) yang merupakan ukuran banyaknya cahaya yang dipantulkan oleh suatu permukaan ke mata.

Sumber penerangan ini berasal dari lampu buatan seperti listrik, gas, atau minyak. Pencahayaan buatan dari suatu tempat kerja bertujuan menunjang dan melengkapi pencahayaan alami, juga dimaksudkan agar suatu ruangan kerja tercipta suasana yang menyenangkan dan terasa nyaman untuk mata. Untuk itu dalam pemilihan atau pengadaan lampu perlu di perhatikan tentang efek dari penerangan buatan terhadap obyek yang di amati, tugas visual tertentu memerlukan penerangan buatan yang lebih baik.

Pada metode lumen yang dibutuhkan adalah data teknis lampu yang didapat dari pabrik pembuat lampu tersebut. Bila data teknis tidak tersedia, dapat dipakai data teknis yang dimuat dalam buku-buku tentang pencahayaan buatan yang akurat. Tahap dari metode lumen ini diantaranya penentuan nilai $\rho c c, \quad \mathrm{CU}$ (Coefficient of Utilization, koefisien penggunaan), $\rho f c, \rho f c$ dan $C U$ dengan nilai yang baru, nilai LLF yang kemudian digunakan untuk penentuan jumlah luminer yang dibutuhkan untuk mencapai tingkat pencahayaan yang standar.

Temperatur merupakan suatu ukuran panas atau dinginnya udara yang pada umunya memiliki satuan Celcius $\left({ }^{\circ} \mathrm{C}\right)$. Saat temperatur lingkungan sangat tinggi dan melebihi Nilai Ambang Batas (NAB) maka dapat berdampak buruk, baik terhadap kesehatan maupun kualitas kerja, terlebih lagi pada saat beban kerja fisik relative cukup tinggi. Menurut Bridger (2003), perbedaan temperatur sebesar sekitar $10^{\circ} \mathrm{C}$ dari temperatur standar sebesar $22^{\circ} \mathrm{C}-30^{\circ} \mathrm{C}$ dapat menyebabkan kinerja aktivitas fisik turun sampai dengan $20 \%$.

Exhaust fan merupakan alat yang berfungsi untuk menghisap udara di dalam ruang untuk dibuang ke luar, dan pada saat bersamaan menarik udara segar di luar ke dalam ruangan. Supaya tetap sehat, suatu ruangan butuh sirkulasi udara agar selalu ada pergantian udara dalam ruangan dengan udara segar dari luar ruangan.

\subsection{Lingkungan Kerja}

Kinerja seseorang dalam melakukan pekerjaannya sering kali bergantung pada lingkungan fisik tempat pekerjaan tersebut dilakukan. Lingkungan kerja adalah keseluruhan sarana dan prasarana kerja yang ada di sekitar pegawai yang sedang melakukan pekerjaan yang dapat memengaruhi pelaksanaan pekerjaan. Lingkungan kerja ini meliputi tempat bekerja, fasilitas dana alat bantu pekerjaan, kebersihan, pencahayaan, ketenangan, termasuk juga hubungan kerja antara orang- orang yang ada di tempat tersebut. Menurut Sunyoto (2012), lingkungan kerja merupakan bagian komponen yang sangat penting bagi karyawan dalam bekerja.

Lingkungan kerja merupakan segala sesuatu yang berada di sekitar tempat kerja yang langsung berhubungan dengan manusia dan lingkungan perantara. Lingkungan kerja yang baik atau kondisi kerja yang mampu memberikan motivasi untuk bekerja akan berpengaruh terhadap semangat karyawan dalam bekerja. Lingkungan kerja dibagi menjadi 
dua jenis yaitu lingkungan kerja fisik dan lingkungan kerja non fisik.

\subsection{Lingkungan Kerja Fisik}

Sebagai makhluk hidup, segala kemampuan manusia dipengaruhi oleh beberapa faktor. Faktor-faktor tersebut bisa datang dari pribadi (intern) atau sebagai akibat dari pengaruh luar (ekstern). Salah satu faktor yang datang dari luar dan akan dibahas lebih rinci ialah lingkungan kerja fisik dimana merupakan tempat manusia melaksakan kegiatan. Berikut ini beberapa faktor menurut (Sedarmayanti, 2011) yang dapat memengaruhi terbentuknya suatu kondisi lingkungan kerja fisik dikaitkan dengan kemampuan karyawan, di antaranya penerangan/cahaya, temperatur, kelembapan, sirkulasi udara, kebisingan, getaran mekanis, bau-bauan, tata warna, dekorasi, musik dan keamanan.

Faktor-faktor pembentuk kondisi lingkungan kerja, diharapkan dapat berguna untuk memajukan teknologi dan ilmu pengetahuan di bidang ergonomi agar kondisi lingkungan kerja di berbagai tempat semakin baik. Dengan kondisi lingkungan kerja fisik yang baik, manusia akan mampu melaksanakan kegiatannya dengan baik sehingga dicapai suatu hasil produksi yang optimal.

\subsection{Pencahayaan}

Setiap pekerjaan baik di kantor maupun di industri, umumnya terdiri atas banyak aktivitas visual. Dalam melakukan pekerjaan apapun, kondisi pencahayaan yang tertata dengan baik akan meningkatkan kemampuan dalam melihat detail dari suatu objek (visual activity) serta meningkatkan kedalaman pandang (depth of field) dari mata.

Intensitas penerangan merupakan suatu aspek lingkungan fisik yang penting untuk keselamatan kerja. Di tempat kerja memerlukan intensitas penerangan yang cukup untuk dapat melihat dengan baik dan teliti. Intensitas penerangan yang baik ditentukan oleh sifat dan jenis pekerjaan dimana pekerjaan yang teliti memerlukan intensitas penerangan yang lebih besar (Suma'mur, 1996). Pencahayaan tempat kerja yang memadai baik yang alami atau buatan, memegang peranan yang cukup penting dalam upaya peningkatan kesehatan, keselamatan dan produktivitas tenaga kerja. Baik tidaknya pencahayaan disuatu tempat kerja selain ditentukan oleh kuantitas atau tingkat iluminasi yang menyebabkan obyek dan sekitarnya terlihat jelas, tetapi juga oleh kualitas dari pencahayaan tersebut diantaranya menyangkut arah dan penyebaran atau distribusi cahaya tipe dan tingkat kesilauan. Demikian pula dekorasi tempat kerja khususnya mengenai warna dari dinding, langit-langit, peralatan kerja, ikut menentukan tingkat penerangan di tempat kerja (Soewarno, 1992). Berikut tingkat pencahayaan minimum yang direkomendasikan untuk berbagai ruangan menurut SNI 03-65752001, terutama untuk ruang dapur seperti pada Tabel 1 dibawah ini.

Pekerja harus dengan jelas dapat melihat obyek yang sedang dikerjakan juga benda atau alat dan tempat di sekitarnya yang mungkin mengakibatkan kecelakaan. Penerangan yang tidak di rancang dengan baik akan menimbulkan kelelahan penglihatan selama kerja.

Tabel 1. Tingkat Pencahayaan Rekomendasi (Badan Standardisasi Nasional, 2001)

\begin{tabular}{lc}
\hline Fungsi ruangan & Tingkat Pencahayaan $(l u x)$ \\
\hline Teras & 60 \\
Ruang Tamu & $120-250$ \\
Ruang Makan & $120-250$ \\
Ruang Kerja & $120-250$ \\
Kamar Mandi & 250 \\
Dapur & 200 \\
Garasi & 60 \\
\hline
\end{tabular}

Pengaruh dan penerangan yang kurang memenuhi syarat akan mengakibatkan dampak sebagai berikut : (1) Kelelahan mata sehingga berkurangnya daya dan efisiensi kerja, (2) Kelelahan mental, (3) Keluhan nyeri atau pegal di daerah mata dan sakit kepala, (4) Kerusakan indera mata dan lain-lain.

\subsection{Pencahayaan Alami}

Pencahayaan alami merupakan patokan untuk mendapatkan penyinaran yang cukup. Patokan ini dapat dihitung dengan faktor langit $(f l)$. Faktor langit adalah angka karakteristik yang digunakan sebagai ukuran keadaan penerangan alami siang hari di dalam suatu ruangan.

Menurut Suma'mur (1996) dalam penggunaan penerangan listrik harus memenuhi syarat-syarat sebagai berikut: (1) Penerangan listrik harus cukup intensitasnya sesuai dengan pekerjaan yang dilakukan. (2) Penerangan listrik tidak boleh menimbulkan pertambahan temperatur udara di tempat kerja yang berlebihan. Jika hal itu terjadi, maka di usahakan temperatur dapat turun, misalnya dengan 
fentilasi, kipas angin, dan lain-lain. (3) Sumber cahaya listrik harus memberikan penerangan dengan intensitas yang tepat, menyebar, merata tidak berkedip-kedip, tidak menyilaukan, serta tidak menimbulkan bayangan yang mengganggu.
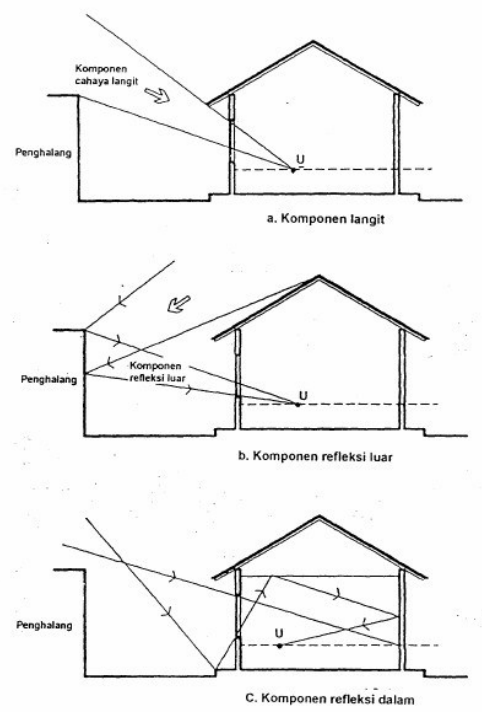

Gambar 1. Komponen cahaya langit yang sampai pada suatu titik di bidang kerja

Dalam pencahayaan buatan, terdapat beberapa istilah yang perlu diketahui, diantaranya : (1) Intensitas cahaya, yaitu kuat dari sumber cahaya dengan satuan candela, (2) Arus cahaya (luminous flux), yaitu banyaknya cahaya yang dipancarkan suatu sumber cahaya ke segala arah dengan satuan lumen (3) Iluminasi, yaitu besarnya arus cahaya yang datang pada satu unit bidang dengan satuan lux (lumen/m2), (4) Luminer, sumber cahaya yaitu lampu, (5) Efikasi, banyaknya arus cahaya yang dihasilkan setiap watt oleh suatu luminer.

Selain istilah dalam pencahayaan buatan, terdapat berbagai jenis lampu/luminer secara umum yang dibedakan menjadi 4 dengan angka efikasi masing-masing sebagai berikut :

Tabel 2. Efikasi Jenis Luminer

\begin{tabular}{lc}
\hline \multicolumn{1}{c}{ Sumber Cahaya } & $\begin{array}{c}\text { Efikasi } \\
\text { (lumen/watt) }\end{array}$ \\
\hline Lampu Pijar (incandescent) & $14-18$ \\
Lampu Halogen & $16-20$ \\
Lampu fluorescent (neon) & $50-85$ \\
Lampu mercury & $40-70$ \\
Lampu metal halide & $60-80$ \\
Lampu sodium & $90-100$ \\
LED & $80-120$ \\
\hline
\end{tabular}

Menurut Sutalaksana, dkk (2006) berbagai tingkat temperatur akan memberikan pengaruh yang berbeda-beda sebagai berikut : (a) 49 derajat Celcius : Temperatur yang dapat ditahan sekitar 1 jam, tetapi jauh diatas tingkat kemampuan fisik dan mental. (b) 29,5 derajat Celcius : aktivitas mental dan daya tanggap mulai menurun dan cenderung untuk membuat kesalahan dalam pekerjaan. (c) 24 derajat Celcius : Kondisi optimum. (d) 10 derajat Celcius : Kelakuan fisik yang ekstrim mulai muncul

\section{METODE}

Pelaksanaan pengabdian masyarakat dilakukan di Sentra Ayam Goreng Kalasan yang beralamat di Jalan Raya Yogya- Solo KM. 14.5, Tirtomartani, Kalasan, Kabupaten Sleman, Daerah Istimewa Yogyakarta 55571. Kegiatan dilaksanakan di salah satu home industri Ayam Goreng Kremes Kalasan $\mathrm{Bu}$ Tatik Widodo dengan jumlah pekerja sebanyak 2 orang. Objek adalah stasiun kerja penggorengan Ayam Goreng Kalasan yang meliputi kegiatan peracikan bumbu, perendaman ayam pada bumbu, penggorengan, dan penirisan ayam goreng. Pencahayaan dan temperatur yang tidak memenuhi standar akan diperbaiki sesuai kebutuhan dengan Metode Lumen (untuk pencahayaan) dan pengukuran kapasitas udara untuk penentuan kipas (untuk temperatur). Pelaksanaan pengabdian dilakukan pada bulan Juni-Juli 2019.

Obyek pengamatan adalah pekerja di Ayam Goreng Kremes Kalasan yang diwawancarai mengenai apa yang dirasakan sebagai dampak dari minimnya pencahayaan dan temperatur. Setelah itu, tingkat pencahayaan di stasiun kerja penggorengan akan diukur dengan luxmeter dan thermometer untuk pengukuran temperatur. Data-data inilah yang kemudian akan diolah untuk merancang lingkungan kerja dengan bantuan lampu dan exhaust fan sesuai kebutuhan.

Tahap-tahap proses perbaikan lingkungan kerja adalah sebagai berikut: (1) Merancang Ulang Pencahayaan, dalam merancang ulang lingkungan kerja fisik dari segi pencahayaan meliputi beberapa tahap, seperti: Menentukan nilai CCR, RCR, dan FCR yang berguna untuk perhitungan langkah selanjutnya. Data yang digunakan untuk menghitung tersebut ialah dimensi ruangan (panjang dan lebar ruangan). Menentukan nilai $\rho c c$, nilai $\mathrm{CU}$, nilai $\rho f c$, nilai pfc 30\% yang berguna bagi penentuan berapa 
lampu yang dibutuhkan untuk mencapai standard. (2) Merancang Ulang Temperatur, dalam merancang ulang lingkungan kerja fisik dari segi temperatur terdapat beberapa tahap yang dilakukan, diantaranya: (a) Menentukan Kapasitas Kipas yang dibutuhkan, (b) Pada tahap ini, dihitung berapa kapasitas kipas yang dibutuhkan pada ruangan dengan menghitung nilai ACR dengan menggunakan data dimensi ruangan, (c) Pemilihan Kipas yang Cocok

Setelah didapat CFM, kemudian disesuaikan dengan spesifikasi kipas angin (exhaust fan) yang cocok untuk ruangan tersebut. (3) Implementasi, perancangan ulang baik dari segi pencahayaan maupun temperatur kemudian akan diimplementasi, setelah itu akan difoto dan direkam ulang untuk dilanjutkan ke analisis hasil. Apabila hasil perancangan belum memberikan perubahan, maka akan dilakukan perancangan ulang. (4) Analisis Hasil, Analisis dilakukan dengan menganalisis hasil pengolahan data perancangan ulang stasiun kerja penggorengan. Analisis lain juga meliputi perbandingan sebelum dan sesudah implementasi fasilitas yang dibuat. (5) Kesimpulan dan Saran, tahap ini merupakan langkah akhir dari penelitian. Didalamnya terdapat penarikan kesimpulan dan saran guna pengembangan penelitian di masa yang akan datang.

\section{HASIL DAN PEMBAHASAN}

Tahap awal dalam adalah dengan melakukan wawancara dengan menanyakan keluhan pekerja. Pekerja yang dituju sebanyak 2 orang. Selain data dari wawancara, terdapat data tingkat pencahayaan dengan menggunakan luxmeter, data temperatur dengan menggunakan thermometer, dan data kecacatan produk berupa ayam goreng yang gosong per hari.

Pengolahan data meliputi penjelasan langkah-langkah perbaikan tentang apa yang dibutuhkan, diantaranya: (a) Perancangan Ulang Pencahayaan, dimulai dengan pembagian nilai untuk perbandingan rongga lantai $(h f)$, rongga ruangan (hr), dan rongga atap (hc), kemudian digunakan untuk mencari CCR, FCR, RCR. Nilai tersebut berguna untuk menentukan nilai $\rho c c$ dan nilai CU. Kemudian nilai $\rho f c$ yang baru ditentukan guna nilai CU yang baru dan setelah didapat nilai LLF, maka dapat ditentukan kebutuhan luminer agar pencahayaan sesuai standar. (b) Perancangan Ulang Temperatur, lingkungan fisik dari segi temperatur dirancang dengan menghitung kapasitas kipas yang dibutuhkan stasiun kerja penggorengan sehingga ditentukan jumlah dan tipe kipas dengan volume udara yang tepat untuk ruangan tersebut.

Analisis hasil, hasil dari pengolahan data menunjukkan perlu adanya perbaikan. Alternatif perbaikan untuk lingkungan kerja fisik yang pertama yaitu dari segi pencahayaan berupa penambahan pencahayaan buatan berupa lampu. Dalam perhitungan untuk mencapai standar pencahayaan, bentuk ruangan di stasiun kerja penggorengan diasumsikan berbentuk kubus. Penggunaan rumus ruangan berbentuk segitiga cukup rumit sehingga hasil dari perhitungan menjadi tidak cukup merepresentasikan jumlah luminer yang dibutuhkan karena terdapat faktorfaktor yang berbeda dengan bentuk ruangan kubus seperti faktor pemantulan cahaya. Alternatif perbaikan lingkungan kerja fisik yang kedua yaitu dari segi temperatur yaitu pengadaan fasilitas berupa exhaust fan. Exhaust fan lebih cocok digunakan guna menyerap udara panas dari dalam stasiun kerja penggorengan dan membuangnya keluar melalui ventilasi yang ada. Pertukaran udara melalui exhaust fan mampu menurunkan temperature dan membuang aroma yang tidak sedap yang ditimbulkan dari bahan-bahan produksi ayam goreng kremes di dalam stasiun kerja penggorengan sehingga sirkulasi udara menjadi lebih baik.

Berdasar pada pengolahan data yang telah dilakukan, jumlah luminer perlu ditambah yang awalnya 2 lampu menjadi 9 lampu berdaya 24 watt dengan 1410 lumen untuk mencapai standar minimal stasiun kerja penggorengan (dapur) sebesar 200 lux namun karena keterbatasan daya pada stasiun kerja penggorengan, maka implementasi hanya digunakan 3 lampu. Lampu yang digunakan adalah DOP 24W. Pada alternatif perbaikan berikutnya, yaitu dari segi temperatur pengadaan exhaust fan disesuaikan dengan kebutuhan kapasitas kipas pada ruangan tersebut atau disebut Cubic Feet per Minute (CFM). Jumlah pengadaan exhaust fan untuk stasiun kerja penggorengan Spectek Exhaust Fan 10"/1 Phase dengan volume udara sebesar 321,41 CFM sebanyak 1 buah.

Setelah didapat kebutuhan guna perbaikan lingkungan kerja, maka kemudian dilakukan implementasi. Dari tingkat pencahayaan di stasiun kerja penggorengan naik dari 10 lux menjadi 72 lux. Dari segi temperatur turun dari 
37,3 oC menjadi 29,7oC. Adanya perbaikan ini juga dirasakan oleh pekerja di stasiun kerja penggorengan Ayam Goreng Kalasan. Dari segi pencahayaan, pekerja merasakan dampak yang cukup signifikan, seperti berkurangnya lelah mata, tidak kesusahan mencari alat-alat masak di dapur saat hari masih gelap, dll. Sedangkan dari segi temperatur, pekerja merasa lebih sejuk, tidak lagi merasakan banjir keringat yang berpengaruh pada kehigienisan ayam goreng, dan merasa nyaman dengan temperatur udara yang ada. Pengaruh yang lebih signifikan dari perubahan lingkungan kerja fisik secara keseluruhan adalah menurunnya jumlah Ayam Goreng Kalasan yang gosong. Awal sebelum perbaikan, dalam satu hari pekerja di Ayam Goreng Kremes Kalasan menghasilkan 15 ekor per hari dengan jumlah ayam yang gosong \pm 8 ekor, kini setelah implementasi diterapkan jumlah ayam yang gosong menurun menjadi 1-2 ekor ayam goreng gosong per hari.

\section{KESIMPULAN}

Kesimpulan dari kegiatan penelitian pengabdian ini adalah: bahwa tingkat pencahayaan di stasiun kerja penggorengan Ayam Goreng Kremes Kalasan sebesar 10 lux dan dari segi temperatur mencapai 37,3oC. Perbaikan lingkungan kerja fisik dari segi pencahayaan dibutuhkan 9 lampu berdaya 24 watt sehingga diimplementasi dengan lampu merk DOP 24W. Rancangan perbaikan dari segi temperatur adalah pengadaan fasilitas Exhaust Fan Spectek Exhaust Fan 10"/1 Phase. Exhaust fan yang dibutuhkan untuk ruangan ini berjumlah 1 buah dengan volume udara 321,41 CFM. Rancangan perbaikan lingkungan kerja fisik tersebut kemudian diimplementasi dan kemudian didapat hasil untuk tingkat pencahayaan, dengan kendala keterbatasan daya maka hanya diterapkan 3 lampu berdaya 24 watt di stasiun kerja penggorengan. Hasil pengukuran pencahayaan di stasiun kerja penggorengan Ayam Goreng Kremes Kalasan menunjukkan angka sebesar 72 lux. Temperatur, diterapkan pengadaan 1 exhaust fan, dan di dapat hasil pengukuran temperatur di stasiun kerja penggorengan Ayam Goreng Kremes Kalasan turun menjadi $29,7^{\circ} \mathrm{C}$.

\section{UCAPAN TERIMA KASIH}

Terimakasih penulis ucapkan kepada LP2M UPN "Veteran" Yogyakarta, yang telah memberikan kontribusi anggaran pengabdian melalui hibah internal.

\section{DAFTAR PUSTAKA}

Amir, A, 2009, Lighting Style, Jakarta: PT Gramedia

Badan Standardisasi Nasional (BSN), 2001, Tata Cara Perancangan Sistem Pencahayaan Buatan pada Bangun Gedung, Jakarta: Badan Standarisasi Nasional (BSN)

Bridger, R, 1995, Introduction to Ergonomics, Singapore: McGraw-Hills

Chengalur, S, 2004, Kodaks Ergonomic Design for People at Work 2nd edition, New Jersey: Jhon Wiley and Sons Inc

Siswanto. 1993, Penerangan, Jakarta: Balai Pelayanan Ergonomi

Sujudi, A, 1999, Persyaratan Kesehatan Lingkungan Kerja, Jakarta: DepKes

Suma'mur, 1996, Ergonomi untuk produktivitas kerja. Jakarta: CV Hajimas Agung

Sutalaksana I.Z., Ruhana A., dan Jann H.T., 2006, Teknik Perancangan Sistem Kerja, Bandung: Penerbit ITB

Wignjosoebroto, S, 2003, Ergonomi, Studi Gerak dan Waktu : Teknik Analisis untuk Peningkatan Produktivitas Kerja, Surabaya: Penerbit Guna WidyaRangkuti, F., 2005, Analisis SWOT Teknik Membedah Kasus Bisnis, PT Gramedia Pustaka Utama, Jakarta.

Wilson, L, 2010, How to Implement Lean Manufacturing. The McGraw-Hill Companies, Inc., United States. 